\title{
Prática de leitura e o livro didático de Língua Portuguesa na Amazônia Tocantina
}

\author{
Reading practice and the Portuguese Language in the Amazônia Tocantina \\ Práctica de lectura y el libro de texto em Portugués em la Amazónia Tocantina
}

Recebido: 31/05/2021 | Revisado: 13/06/2021 | Aceito: 15/06/2021 | Publicado: 29/06/2021

\author{
Andrea Silva Domingues \\ ORCID: http://orcid.org/0000-0002-9264-7754 \\ Universidade Federal do Pará, Brasil \\ E-mail: andrea.domingues@gmail.com \\ José Alcir Wanzeler Prestes \\ ORCID: http://orcid.org/0000-0002-2673-995X \\ Universidade Federal do Pará, Brasil \\ E-mail: josealcir13@gmail.com \\ Bruno César Castello Ananias \\ ORCID: http://orcid.org/0000-0002-5632-005X \\ Universidade Estadual de Campinas Brasil \\ E-mail: b.castello@hotmail.com
}

\begin{abstract}
Resumo
Este artigo tem como objetivo específico apresentar uma análise do funcionamento da linguagem na/da prática de leitura em sala de aula e seu sentido no aprendizado do sujeito-aluno a partir do uso do livro didático de Língua Portuguesa intitulado "Tecendo Linguagens" — PNLD (2017-2019) — utilizado no 9 ano do Ensino Fundamental da escola ribeirinha localizada na ilha Pacuí, na cidade de Cametá, Pará. Metodologicamente, realizamos uma pesquisa qualitativa e analítica do discurso, utilizando dos dispositivos teórico-metodológicos da Análise de Discurso. Filiados a uma perspectiva discursiva, analisamos os elementos de apresentação (sumário e capa) e a construção do conjunto de imagens do livro didático; material que forneceu evidências discursivas importantes para que pudéssemos trazer na construção da narrativa deste texto, a necessidade emergencial de pensarmos novas formas de ler, de praticar a leitura no espaço escolar, além do livro didático e de um projeto capitalista, urbanizado que se distancia totalmente da realidade do sujeito-aluno que vive na Amazônia Tocantina.
\end{abstract}

Palavras-chave: Leitura; Discurso; Língua portuguesa; Livro didático.

\begin{abstract}
This article has as specific purpose to present an analysis of how language works in/on the practice of reading in the classroom and its meaning in the learning of the subject-student from the use of the Portuguese Language textbook entitled "Tecendo Linguagens" - PNLD (2017-2019) - used in the 9th grade of elementary school in a riverside school located on Pacuí Island, in the city of Cametá, Pará. Methodologically, we conducted a qualitative and discourse analytical research, using the theoretical and methodological devices of Discourse Analysis. Affiliated to a discursive perspective, we analyzed the elements of presentation (summary and cover) and the construction of the set of images of the textbook; material that provided important discursive evidence so that we could bring in the construction of the narrative of this text, the urgent need to think about new ways of reading, of practicing reading in the school space, beyond the textbook and a capitalist project, urbanized that is totally distant from the reality of the subject-student who lives in the Amazônia Tocantina
\end{abstract}

Keywords: Reading; Discourse; Portuguese language; Didactic book.

\section{Resumen}

Este artículo tiene como objetivo presentar un análisis del funcionamiento del lenguaje en la práctica de la lectura en el aula y su significado en el aprendizaje del sujeto-estudiante del uso del libro de texto en portugués titulado "Tejer idiomas" - PNLD (2017-2019) - utilizado en el noveno año de escuela primaria de la escuela ribereña ubicada en la isla Pacuí, en la ciudad de Cametá, Pará. Metodológicamente, realizamos una investigación cualitativa y analítica del discurso, utilizando los dispositivos teórico-metodológicos del Análisis del Discurso. Afiliados a una perspectiva discursiva, analizamos los elementos de presentación (resumen y portada) y la construcción del conjunto de imágenes en el libro de texto; material que proporcionó importantes pruebas discursivas para poder aportar la construcción de la narrativa de este texto, la necesidad urgente de pensar en nuevas formas de leer, practicar la lectura en el espacio escolar, además del libro de texto y un proyecto capitalista, urbanizado que está totalmente alejado de la realidad del estudiante sujetio que vive en la Amazonía Tocantina.

Palabras clave: Lectura; Discurso; Idioma portugués; Libro de texto. 


\section{Introdução}

O livro didático é um dos recursos utilizados pelos professores em sala de aula e, como produção cultural do conhecimento, oferece um conjunto de textos e imagens que podem gerar diferentes tipos de leituras, análise e interpretação das relações e realidades do mundo social e cultural dos sujeitos, uma vez que a leitura ultrapassa os limites existenciais humanos. Os textos independem do sujeito-aluno e "quando se pensa em um livro didático de qualidade é preciso primeiro fazer um processo de desconstrução da obra didática, desvelando, portanto, os interesses existentes na elaboração nas obras e sua influência no comportamento dos jovens e a sua imagem do mundo advinda do livro didático" (Monteiro, Juca \& Silva, 2019, p. 9).

Desta forma, compreendemos que os livros didáticos têm importância na medida em que oferecem conteúdos críticos, voltados para os interesses dos alunos e suas realidades sociais. É importante frisar que as escolas públicas recebem as obras referentes ao Programa Nacional do Livro Didático - PNLD. Uma aquisição realizada pelo Fundo Nacional de Desenvolvimento da Educação - FNDE sob o critério de avaliação do Ministério da Educação. Uma das formas pelas quais os professores e alunos podem contar com materiais de qualidade física e pedagógica para os exercícios das atividades escolares.

Neste texto, propomos realizar um exercício de análise discursiva de alguns elementos gerais de apresentação (capa e sumário) e da construção do conjunto / distribuição das imagens no livro didático, intitulado Tecendo Linguagens, adotado nas aulas de Língua Portuguesa do $9^{\circ}$ ano do Ensino Fundamental, elaborado por Tania Amaral Oliveira Silva, Elizabeth Gavioli de Oliveira Silva, Cicero de Oliveira Silva e Lucy Aparecida Melo Araújo. Material didáticodistribuído na Escola Municipal de Ensino Fundamental Professor João Teixeira Távora na ilha do Pacuí, no município de Cametá, Pará.

\section{Os Instrumentos Teóricos e Metodológicos Mobilizados}

Para o desenvolvimento teórico-metodológico deste texto, tomamos como foco central o diálogo entre Educação, Análise de Discurso e História Social, tendo como ponto de partida que as três áreas do saber vêm contribuindo fortemente com metodologias de análises para compreensão da linguagem e da historicidade na/da educação brasileira.

Nosso lócus de pesquisa foi a sala de aula. Turma do $9^{\circ}$ ano do Ensino Fundamental de uma escola pública ribeirinha, a saber, na E.M.E.F. Professor João Teixeira Távora que está vinculada à Rede Municipal de Ensino do município de Cametá localizado a $150 \mathrm{~km}$ da cidade de Belém, capital do Estado do Pará.

A cidade de Cametá, conforme o censo do Instituto Brasileiro de Geografia e Estatística-IBGE de 2010, teve sua população com o número de 120.896 e uma estimativa para 2019 de 137.890. Referente à educação, os dados do IBGE (2020) apresentados publicamente, concernentes ao ano de 2018, foram para o Ensino Fundamental, um total de 208 escolas com 28.556 matrículas e 1511 professores para atuar; e no Ensino Médio, foram identificadas 13 escolas com um total de 6.096 matrículas e 218 professores para atuar. É importante destacarmos que estamos falando de uma região amazônica entre florestas, rios e igarapés, onde a maioria da população se concentra em comunidades distantes da cidade; residem em ilhas, comunidades tradicionais, quilombolas, indígenas, em regiões entre rios e florestas; são sujeitos que procuram a cidade para revender seus produtos provenientes de suas relações com a natureza, motivo de sobrevivência.

Metodologicamente, realizamos uma pesquisa qualitativa e analítica do discurso, utilizando dos dispositivos teóricos da Análise de Discurso de linha francesa, proposta pelo filósofo francês Michel Pêcheux, que "é o fundador da Escola Francesa de Análise de Discurso" (Orlandi, 2005, p. 10), e pela linguista brasileira Eni Puccinelli Orlandi, na teorização e ampliação de sua obra (Orlandi, 2012, p. 37-49).

Adotamos o método qualitativo porque este: 
[...] se contrapõe ao esquema quantitativo de pesquisa (que divide a realidade em unidades possíveis de mensuração, estudando-as isoladamente), defendendo uma visão holística dos fenômenos, isto é, que leve em conta todos os componentes de uma situação em suas interações e influências recíprocas (Ludke \& André, 1986, p. 17).

A opção pela pesquisa qualitativa é por esta possibilitar ao pesquisador uma visão holística, considerar a flexibilidade de investigar o objeto de estudo, levando em conta a dinâmica, prevendo as necessidades de modificar alguns fenômenos da pesquisa como, por exemplo, as mudanças de ações dos sujeitos envolvidos na investigação. Trata-se de processos contínuos do refazer e repensar os caminhos para se chegar a uma determinada conclusão na construção dos conhecimentos relativos às necessidades humanas.

Para Alves Mazzotti e Gewandsznnajder (2002, p. 147), "as investigações qualitativas, por sua diversidade e flexibilidade, não admitem regras precisas, aplicáveis a uma ampla gama de casos". A leitura e a atuação das práticas de ensino de língua portuguesa que estão relacionadas a um contexto que envolve o social, o histórico e a cultura, apresentam dimensões dinâmicas e relativas na produção da formação dos conhecimentos.

Contudo, é necessário pensar o objeto da pesquisa e não antecipar qualquer situação do que possa ser investigado, pois o foco da pesquisa vai criando os rumos dos processos de investigação, de maneira que os movimentos e articulações criados a partir do objeto de estudo podem caracterizar a ação.

É importante ressaltar que a realização desta pesquisa foi fundamental para podermos compreender os diferentes discursos e sentidos que atravessam o livro didático da disciplina de Língua Portuguesa dentro de um espaço escolar que atende filhos de trabalhadores ribeirinhos, das florestas e das águas. As consequências destes discursos podem interferir no processo de construção identitária do sujeito-aluno.

Ao nos propormos realizar uma análise discursiva do LD de LP neste texto, devemos ressaltar que a Análise de Discurso não será aqui adotada como um método, mas sim como uma disciplina de interpretação da qual elegemos dispositivos teórico-analíticos para interpretação de nosso corpus de análise. Assim, é importante considerar que a Análise de Discurso trabalha diretamente com o funcionamento do discurso, não diretamente com a gramática da língua, mas sim observa todos os sujeitos envolvidos, o movimento do discurso, a construção do acontecimento e o que está a sua volta. O discurso é assim: palavra em movimento, prática de linguagem; é a língua fazendo sentido, é o sentido do discurso e seu funcionamento, a partir de suas articulações ideológicas (Orlandi, 2010).

\section{Língua Institucionalizada e Discurso no/do Livro Didático}

Para compreensão da prática de leitura no espaço escolar é necessário que compreendamos como esta prática funciona e qual sua relação com a língua que é considerada por estes pesquisadores como um acontecimento social em constante movimento, interagindo com o que está ao seu redor, afetando os sujeitos e sendo afetada de diferentes formas por fatores sociais, políticos, ideológicos, institucionais e/ou históricos, que vivem em constante disputa pelo funcionamento do discurso e automaticamente da/na linguagem, da língua e da memória, "afinal os processos identitários se fazem em diferentes espaços de memória” (Domingues, Pinto \& Docema, 2019, p. 337).

O sujeito-aluno, ao adentrar no mundo escolar, traz consigo memórias, palavras e discursos permeados de historicidades e são falantes, pois nasceram na linguagem e, no espaço de ensino institucionalizado, passam a ter contato com uma língua também institucionalizada, a Língua Portuguesa, convencionalizada como padrão apenas esta quando ensinada nos bancos escolares. 
Esta língua institucionalizada é a que se pretende que seja ensinada na Escola. A língua correta. Normatizada. O discurso dominante sobre a língua, na sociedade capitalista, é o da língua institucionalizada, a que tem correção, regularidade e unidade. Esta unidade é a unidade da língua nacional. Desse modo, identifica-se o aluno bem formado com aquele que fala a língua institucionalizada, reconhecida na sociedade como a língua legítima. A que, no "imaginário social", se aprende na escola, instituição do Estado que individua o sujeito como sujeito alfabetizado, escolarizado, o que sabe a língua que fala. Ou fala de acordo com a norma (Orlandi, 2014, p. 158).

É com um olhar que busca compreender o sujeito-aluno e as formas de ensinar além de um saber institucionalizado, normatizado que valoriza apenas a língua que o Estado reconhece, é que nos colocamos em um posicionamento político e histórico, que não exclui e olha além do espaço institucionalizado, pois valoriza o sujeito-aluno, suas práticas cotidianas e seus saberes não formais, principalmente suas práticas de linguagem que entre florestas e rios avançam aos saberes formais, com formas de saber fazer, falar e viver próprias da Amazônia Tocantina.

Ao sujeito-aluno ter contato com o espaço escolar, com o saber institucionalizado, ele está sendo assujeitado a um discurso de formação e ao mesmo tempo a um "discurso pedagógico" (Orlandi, 2009, p. 28) que é aquele que instaura "um dizer institucionalizado, sobre as coisas" (idem), porém não é eliminado o que está em sua memória, o que foi dito e vivido antes. Suas experiências de vida passam a conviver em conjunto com esse novo espaço simbólico, de representações, pois:

Sujeito e sentido se constituem simultaneamente", ou seja, ao ser introduzido no mundo simbólico, esse sujeito se torna assujeitado a um discurso que vai sendo construído sobre e por ele enquanto ele toma contato com a linguagem, mesmo porque é pela língua que o discurso se materializa (Orlandi, 2007, p. 27).

Sabe-se que o sujeito-aluno possui sua língua materna que, conforme Guimarães (2006), é a língua cujos falantes a praticam pelo fato de a sociedade em que se nasce a praticar. Nesta medida, ela é, em geral, a língua que se representa como primeira para seus falantes, ou seja, é a língua que toca os sujeitos em sua autonomia, em sua identidade,em sua autodeterminação (Orlandi, 2005); e é pelo discurso que a língua se materializa. Deste modo, analisar o livro didático de Língua Portuguesa (língua institucionalizada), ratificada pelo "discurso pedagógico" (Orlandi, 2009, p. 28) e sua relação com a prática de leitura se faz fundamental para compreensão dos sentidos das atividades de leitura em sala de aula para o sujeito-aluno, principalmente, o ribeirinho da Amazônia Tocantina.

A língua é produtora de sentidos que se constituem na relação do sujeito com o ideológico e o histórico, mediada pelo simbólico; desta forma, não podemos considerar que se adquire uma língua, mas que nos inscrevemos nela "no instante, em que a língua é tomada pelo sujeito. Assim, o sujeito já tem, desde sempre, sua língua materna, ele não a adquire, pois é sujeito de linguagem" (Pfeiffer, 2005, p. 33). O sujeito e a língua se constituem juntos, sendo o sujeito afetado pela ideologia. Dessa forma, a língua é a materialidade específica do discurso, funcionamento que está muito além da noção de língua institucionalizada.

O aprender a ler e a escrever no espaço escolar deve exigir uma participação ativa da escola, dos professores de Língua Portuguesa, dos orientadores educacionais, principalmente dos pedagogos (as) que têm em mãos um aparato teóricometodológico eficiente para que o sujeito-aluno torne-se de fato um autor e um leitor que conheça e tenha domínio de certos mecanismos discursivos a fim de que compreenda em que ordem social está inserido e o que se exige dele dentro do sistema capitalista; somente assim, o sujeito-professor pode atuar de maneira que leve o sujeito-aluno a se engajar neste processo e não apenas aprender a escrever ou aprender a ler para atender a uma ideologia de Estado que normatizou e o assujeitou a regras; regras estas que devem ter o engajamento do sujeito-aluno no ato de aprender a partir de seus conhecimentos, de suas práticas discursivas.

Em nossas pesquisas de campo, dialogávamos informalmente com um senhor, pescador, que nos acompanhava em meio à navegação. Ao saber de nosso objetivo de pesquisa, logo respondeu que "a leitura é muito importante em nossa vida, 
nos ajuda aprender o que é esse mundo". Mesmo as narrativas orais não sendo o foco de composição de nosso corpus de análise, compreendemos ser importante trazer a narrativa deste sujeito social parao texto deste artigo, pois a percepção do saber ler para ele avança o espaço institucionalizado. A leitura para este sujeito tem o sentido amplo de conhecimentodo mundo, não somente do que está nos bancos escolares, pois o pescador ainda fez questão de afirmar que "considero importante a leitura para o aluno, ele faz independente, porque a gente não tem muitos estudos para ajudar eles". O saber ler está vinculado para aquele sujeito à liberdade, à independência; ou seja, o sujeito, ao praticar a leitura, consegue conhecer o mundo e assim ser livre para sobreviver visto que a leitura, conforme ensinamentos de Orlandi (2010), é uma práxis que tem intrínseca a interpretação, pois somos sujeitos de linguagem e estamos fadados a interpretar. E ainda de acordo com a autora, "ler é saber que o sentido pode ser outro" (Orlandi, 2012, p. 15). É por esta nova inscrição dos sentidos dada no espaço da leitura, no lócus da interpretação, no equívoco da língua que o sujeito sobrevive via sua independência, via sua liberdade, já que seu pai, o pescador, não pode ajudá-lo por não ter muitos estudos.

$\mathrm{Na}$ narrativa do pescador, o significado da leitura é forte, vinculado ao saber viver e necessário para ser livre, independente; é importante para apreender o mundo. A leitura seria um dos instrumentos básicos no desenvolvimento humano, porque abriria caminho para ampliar a visão de mundo e realidade do homem na sociedade (Freire, 2019).

São pelas palavras, como a deste pescador, trabalhador das águas e das matas desta Amazônia Tocantina, que como educadores e pesquisadores sociais nos motivamos a cada dia a pensar na prática de leitura como um direito social, pois como nos afirma Silva (2000, p.675) "ler é um direito de todos e, ao mesmo tempo, um instrumento de combate à alienação e à ignorância”.

O livro didático é um dos principais instrumentos de auxílio dos professores em sala de aula, principalmente para a prática da leitura dos alunos do Ensino Fundamental. Ao termos contato com os textos, imagens e toda a estrutura do livro didático do $9^{\circ}$ ano da E.M.E.F. Prof. João Teixeira Távora, observamos que o livro tem uma estrutura linguística discursiva, que seus enunciados trazem discursos ideológicos que produzem sentidos, construindo, assim, uma relação sujeito autor - leitor.

Em muitos momentos, o livro didático acaba sendo um reprodutor de discursos, ou seja, funciona como um objeto de controle do Estado, que é o responsável pela escola pública e pelo projeto político educacional implantado no Brasil. Neste contexto, para interpretação do material didático, ou seja, o livro de Língua Portuguesa utilizado na E.M.E.F. Prof. João Teixeira Távora, buscamos observar o que está escrito, representado imageticamente no livro e quais sentidos produzem no sujeito-aluno ribeirinho, na constituição da leitura, sempre considerando que as palavras não têm um sentido literal, elas se significam em uma determinada formação discursiva (Orlandi, 2003).

Daremos início, agora, ao nosso exercício de análise para este texto, a reflexão sobre as imagens contidas no livro didático adotado para o $9^{\circ}$ ano da escola ribeirinha da ilha Pacuí em Cametá, no período de 2017 a 2019. 
Figura 1 - Capa do livro didático "Tecendo Linguagens".

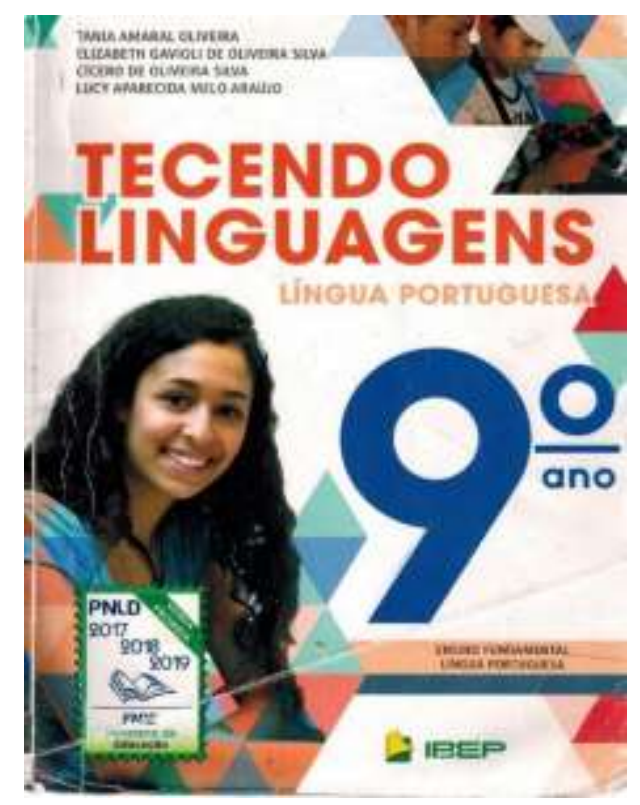

Fonte: Oliveira, Silva, Silva e Araújo (2015).

A Figura 1 se refere à capa do livro intitulado Tecendo Linguagens. Traz a ilustração de uma adolescente e dois meninos. Um dos meninos está mostrando ao outro, possivelmente, imagens de uma câmera fotográfica. O livro em si, pela capa, possivelmente permite uma leitura diversificada, começando pelas cores, pelos sujeitos que apresentam boas aparências, como também pela palavra linguagens que está no plural; tentando, a partir de nossa interpretação, representar as diversas formas de leituras e falas. Porém, observou-se que mesmo havendo possibilidades outras de interpretação, de leitura, a homogeneidade na construção do livro didático se apresenta já pela sua capa que, de acordo com Gadet e Pêcheux (2010), procura instaurar o efeito de estabilização para os gestos de leitura, porém não o pode devido à própria desestabilização dos sentidos. Mesmo com o efeito de sentidos de um universo plural, ainda prevalecem as ideias acerca de um determinado tipo de sujeito e leitura, neutralizando outras existências na escola e na sociedade que, segundo Orlandi (2010), são possibilidades que escapam ao efeito de transparência da linguagem e, conforme Gadet e Pêcheux (2010), escapam ao efeito de estabilidade dos sentidos.

O livro Tecendo Linguagens de Língua Portuguesa, na sua apresentação para o aluno (a) reconhece esta percepção do não conhecimento do sujeito, mas propõe imaginar que seja de fato, curioso (a) o aluno (a) para saber do que se trata nas páginas do livro, bem como oferecer uma conjuntura ampliando, assim, a visão de mundo e realidade social.

O livro didático foi escrito com a intuito de contribuir com a formação dos alunos no ensino de Língua Portuguesa; visa, com isso, trabalhar de maneira individual ou coletiva a fim de se relacionar com os sujeitos que estão ao seu lado, nos espaços de convivênciasque permitem as trocas de experiências e os compartilhamentos de conhecimento.

O livro didático, segundo os autores, traz algumas ferramentas importantes para tornar as atividades de ensino de leitura mais dinâmicas, agradáveis e cheias de surpresas. O que poderá levar os alunos a terem mais interesse pelo ensino e pelo aprendizado da Língua Portuguesa no âmbito do contexto da sala de aula.

O propósito do livro é permitir que os indivíduos utilizem suas habilidades e capacidades para desenvolver os hábitos da leitura, evidenciando a manifestação do sentimento e das sensações e também possam registrá-los através de prática de ensino que os levem à construção e à reconstrução de história de vida, aprendendo a defender suas opiniões oralmente e por escrito, como resultados do pensamento e linguagem. 
Logo no início do livro, em suas primeiras páginas, os autores trazem para o leitor o enunciado "Conheça seu Livro". A expressão "prática de leitura" vem em destaque neste apresentar da obra didática, já anunciando ao sujeito-aluno que é pelo livro que se irá trabalhar a prática de leitura em sala de aula. Contudo, para o exercício desta prática deve-se haver antes o momento do ler; por dentro do texto; trocando ideias; confrontando o texto e sua construção. Todo o processo de construção da prática de leitura do sujeito-aluno vem "ditada" de como deve ser realizada, devendo este seguir as etapas ali explicitadas, ou seja, como se a prática de leitura funcionasse de uma única maneira em todos os sujeitos da mesma forma e com o mesmo sentido. "A escola se institui por regulamentos, por máximas que aparecem como válidas para a ação, como modelos” (Orlandi, 2009, p. 28).

Ao dar continuidade ao nosso estudo do livro didático como corpus de análise, consideramos importante destacar o sumário desta obra, em que estão descritas todas as propostas de atividades a serem desenvolvidas nas aulas de Língua Portuguesa. Algo que muito nos chamou a atenção é a repetição da expressão "prática de leitura" que aparece em 33 (trinta e três) páginas de um total de 284 (duzentos e oitenta e quatro) páginas que totalizam o livro didático.

Mais de $11 \%$ (onze por cento) das páginas de atividades do material didático trazem o enunciado "prática de leitura", após o título do capítulo; antes de iniciar qualquer atividade proposta em sala de aula e do subtítulo "Para começo de conversa". Observamos que há uma repetição constante da expressão "prática de leitura", funcionando como uma retomada de sentidos, tentando retomar a ideia de que algo pode surgir de novo. Contudo, entendemos que repetir não é reproduzir, ou seja, na tomada de sentidos há deslizamentos e construção de outros significados, constituindo desta forma o processo discursivo (Pêcheux, [1983] 2008).

O livro didático, nos últimos anos, tem mudado o seu formato e conteúdo, porém pode-se observar que ainda há muitas formas para se exercitar e ensinar a Língua Portuguesa. Mais do que isto, é necessário identificar concepções teóricas e metodológicas das quais os autores (as) se valem para expor suas ideias. O papel da escola e do professor (a) é organizar as atividades a partir de um planejamento adequando que deve ser discutido e elaborado em uma gestão democrática, juntamente com o pedagogo (a) e com a comunidade escolar como um todo. Assim, seus conteúdos atenderão as necessidades dos alunos, uma vez que as realidades sociais e culturais influenciam no aprendizado.

A prática de leitura é um acontecimento de interpretação, assim sendo um acontecimento discursivo, através do qual há todo um processo sendo constituído; ou seja, há sempre, conforme Pêcheux ([1983] 2008), a instauração de sentidos novos na atualização constante da memória e do dizer. É neste espaço de discurso que buscamos compreender a prática de leitura do sujeito-aluno e como o livro didático participa deste acontecimento, como pode ser observado na Figura 2. 
Figura 2 - Esquema de Prática de Leitura.

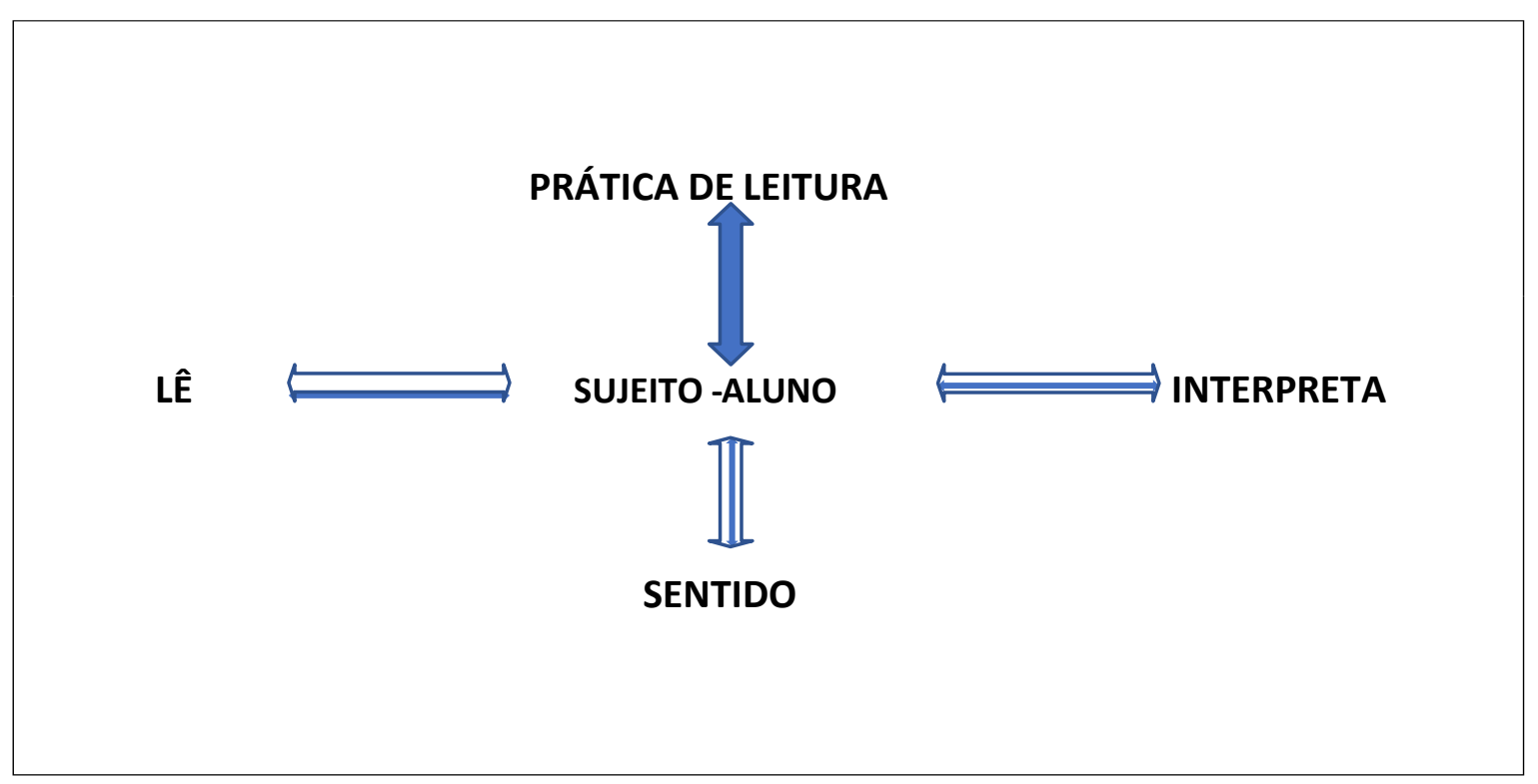

Fonte: Domingues, A. S. (2020).

Diferentemente de um acontecimento histórico que marca o fato, o acontecimento discursivo avança os registros e a estrutura. Este busca os entremeios na perspectiva discursiva da interpretação, olhando o fato como discurso. $\mathrm{O}$ acontecimento discursivo busca a relação entre dizeres, o cruzamento, as rupturas, o novo dizer, compreendendo os novos espaços de significação (Dela-Silva, 2008).

A prática de leitura sempre estará funcionando no esquema apresentado: sujeito-aluno que lê, interpreta e produz sentidos no processo de constituição da leitura. E é neste acontecimento discursivo que memórias são ativadas, instaurando sentidos na produção do discurso e da/na interpretação.

O livro didático "Tecendo Linguagens" traz diferentes tipos de leituras e concepções de sujeitos nas propostas de produção de texto: trabalho, valores, hábitos, costumes e comportamentos inerentes às necessidades dos indivíduos, uma vez que as variações de linguagem e pensamentos são manifestadas a partir das realidades do mundo social.

O livro didático é uma construção histórica e cultural permeada de forças e relações contraditórias que envolvem pessoas e concepções diferenciadas de conhecimentos e conceitos referentes à leitura, pois a própria fala deixa em parte de ser uma materialização de "todos" para a detenção do monopólio de alguns que mantêm e controlam as relações de poder. No entanto, podemos compreender que não só o livro didático, mas também a escola e o sistema de ensino contribuem à manutenção de tal monopólio. Bourdieu (1974, apud Orlandi 2009) formula que a escola (com todos os seus aparatos, inclusive o livro didático) e o sistema de ensino são "soluções dissimuladas" para a relação da transmissão de poder, pois contribuem à permanência das relações de classe, mascaradas por meio de uma pseudoneutralidade de sua função social.

Com um olhar mais atento à interpretação do livro didático, alguns fatores nos chamaram a atenção quando consideramos que os sujeitos são seres produtores de cultura, discurso e memória. Ancorados em Orlandi (2010), compreendemos que são sujeitos sociais, históricos e simbólicos que se movem e reclamam por sentidos para se inscreverem na história.

Entendemos que o livro didático se constitui de e pela linguagem e que participa da constituição do sujeito-aluno pela prática de linguagem. Os discursos sempre estão sendo mobilizados e os sujeitos historicizados neste material didático. Isso conduziu estes educadores a terem um olhar além daquilo que é escrito no livro didático; um perceber além daquele anunciado 
no material; levou-nos ater um "olhar político" (Sarlo, 2016, p.17). Um olhar que, embora aponte e recorde a história, não a vê como um depositário de datas e fatos. Pelo contrário, o olhar político confere à história um olhar crítico capaz de enxergar as relações entre o presente e o passado; um olhar que coloca em destaque as diferenças e descobre nelas as disputas ideológicas, a política dos sentidos (Orlandi, 2010), entendendo-as como um acontecimento.

A linguagem é um ponto comum na relação sujeito e sociedade, principalmente como forma de manifestação social, política e ideológica, e o material didático é um dos instrumentos mais utilizados até o tempo presente pelos professores para a prática de leitura na sala de aula; por ser este o instrumento entregue gratuitamente pelo governo aos alunos que frequentam o sistema de ensino público. A escola denominada pública, que na verdade é uma escola do Estado, pois é regida e controlada por políticas governamentais que representam uma ideologia, que atende aos interesses de uma determinada classe que, na conjuntura atual, na interpretação destes pesquisadores, não é a classe trabalhadora e muito menos a dos filhos de ribeirinhos que frequentam a escola da ilha do Pacuí em Cametá, Pará. Portanto, compreender os usos da memória, interpretar os discursos no material didático torna-se uma tarefa de extrema importância no processo educacional.

Para melhor apresentar ao leitor como foi distribuída as imagens que poderiam abordar a realidade do aluno e seu cotidiano no livro didático de Língua Portuguesa utilizado no $9^{\circ}$ ano da E.M.E.F. Prof. João Teixeira Távora, na ilha do Pacuí em Cametá, Pará; bem como para que possamos, assim, pensar quais os possíveis sentidos da prática de leitura instaurados pelo livro didático no sujeito-aluno, vejamos o Gráfico 1.

Gráfico 1 - Representação imagética no livro didático.

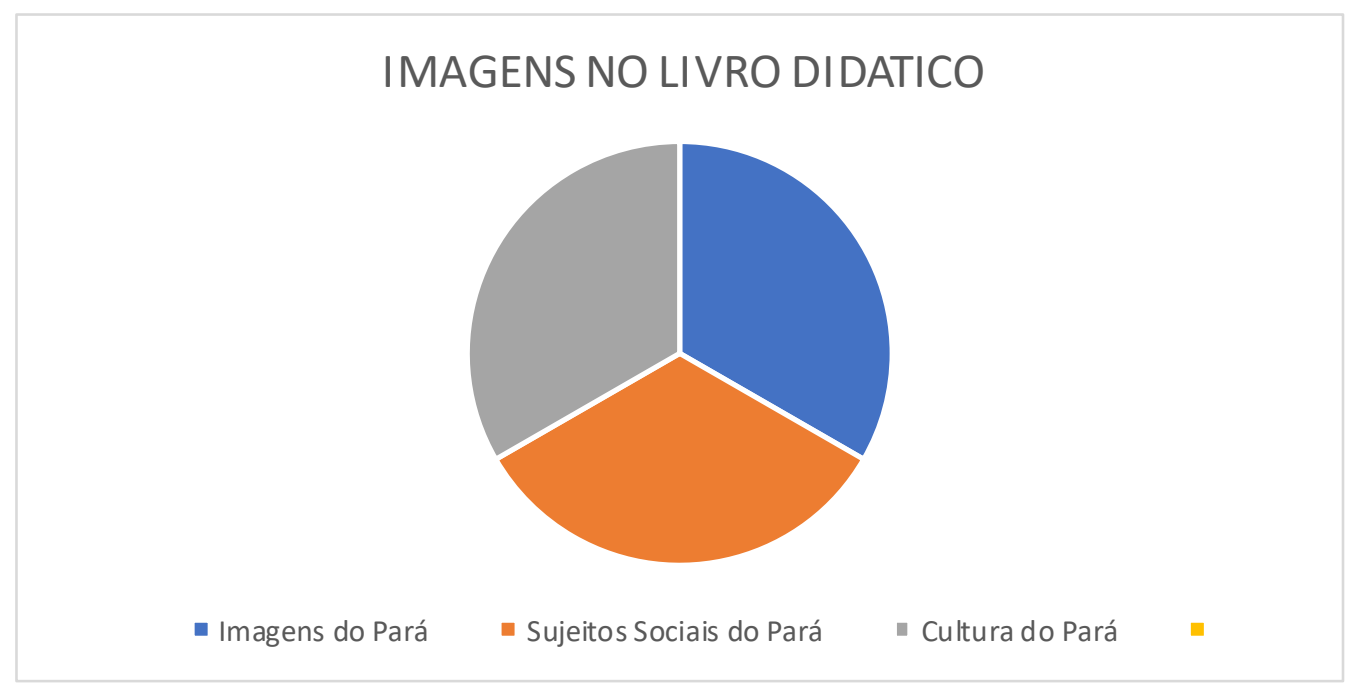

Fonte: Prestes, J. A. W (2020).

No Gráfico 1, de um total de 284 páginas do livro “Tecendo Linguagens” de Língua Portuguesa dos alunos do $9^{\circ}$ ano que moram na zona rural de terras ilhadas e matas da Amazônia Tocantina, no norte do Brasil, no estado do Pará, os quais possuem práticas culturais específicas permeadas de saberes que dialogam com a natureza, de uma historicidade afro-indígena rica de sabores e cheiros, de modos de se dizer, falar, de técnicas de caminhar e navegar; ou seja, um cotidiano totalmente diferente da região sul-sudeste brasileira. Das 284 páginas, apenas 06 (seis) tratam especificamente de algum assunto que liga diretamente as questões identitárias do sujeito-aluno da Amazônia brasileira; e dentre essas, 02 (duas) dos sujeitos sociais, 02 (duas) de lugares e 02 (duas) de um aspecto cultural regional.

Apenas $2 \%$ do livro didático traz de forma bem suscinta algum conteúdo da realidade do sujeito-aluno paraense; e ao estar inserido na sala de aula praticando a leitura, ele se torna assujeitado ao discurso ali contido, porque, conforme 
depreendemos de Orlandi (2010), o político, na clivagem dos sentidos e dos sujeitos, determina o que deve ou não ser dito ou compreendido. Mas este aluno também já é um portador de memórias, pois ele é constituído na e pela linguagem e por sua realidade vivida. O aluno, ao ir à escola praticar a leitura, já traz consigo saberes, discursos, pois ele vem de uma formação discursiva que produz sentidos para ele, porque a vida para este aluno é um "acontecimento discursivo" (Pêcheux [1983], 2008), já que ele atualiza incessantemente os sentidos de sua vivência pela prática de leitura; e na memória dele, corroborando com Orlandi (2010), algo fala, algo diz de si, independentemente, e em algum lugar.

Neste contexto, o material didático deixa de explorar a realidade do sujeito-aluno e torna-se um material obrigatório de uso, normatizado, sem atrativo, sem sentido para o aluno, pois como abordado por Massmann (2013, p. 166) "mesmo no século XXI, as práticas pedagógicas escolares continuam se instituindo e ordenando o que se deve saber, impondo desta forma produção e sentidos". O livro didático ainda representa os interesses ideológicos do Estado não estimulando a criatividade do aluno. A prática de leitura funciona pela identificação, ou seja, como uma forma de necessidade identitária, como um ato de resistência para manter suas formas de viver, suas práticas culturais, seus saberes, não somente pela oralidade, mas também pela escrita e pelo ato de ler. Como nos disse o pescador, citado no início deste texto "a leitura para o aluno faz ele independente",e um sujeito independente é livre para pensar e decidir os rumos de seu país sem se submeter a políticas fascistas, lutando incansavelmente por uma educação de qualidade e gratuita para todos e todas.

O livro didático de Língua Portuguesa utilizado nas escolas ribeirinhas de Cametá, como todos os outros do Brasil, são produzidos pelo Ministério da Educação e Cultura (MEC) e distribuídos gratuitamente para as escolas públicas do país. Estes livros seguem os Parâmetros Curriculares Nacionais para o Ensino de Língua Portuguesa; contudo, após nossa análise das imagens contidas no livro, observamos que para as atividades de prática de leitura as especificidades regionais e a questão identitária do aluno não foram contempladas no livro "Tecendo Linguagens" do $9^{\circ}$ ano utilizado na Escola Municipal de Ensino Fundamental Professor João Teixeira Távora, localizada na ilha Pacuí em Cametá, Pará. O livro didático não explora as práticas cotidianas e culturais dos povos amazônicos; não privilegia o universo discursivo do sujeito-aluno ribeirinho, deixando de fazer da prática de leitura um momento de troca de saberes, de mobilização de sentidos, permitindo-se constituir pela simples reprodução de discursos.

\section{Algumas Considerações Finais}

A pesquisa constatou que no livro didático "Tecendo Linguagens" ofertado pelo Programa Nacional do Livro Didático (PNLD) de 2017-2019, utilizado nas aulas de Língua Portuguesa do $9^{\circ}$ ano do Ensino Fundamental na E.M.E.F. Prof. João Teixeira Távora da ilha Pacuí, no município de Cametá, Pará, a reprodução dos conhecimentos apresenta um determinado discurso sobre o ensino de Língua Portuguesa e a aprendizagem da leitura que não situa as realidades dos alunos, pois trata, muitas vezes, de outros contextos e situações de vivências, falas e linguagens diferentes, o que de certo modo impacta na aquisição do aprendizado e desestimula a criatividade do aluno (a).

A prática de leitura realizada no espaço institucional de ensino para os ribeirinhos no tempo presente, a partir da interpretação de nosso corpus de análise, demonstra que da forma como é realizada, pautada no material didático, pode distanciar os alunos do processo de se identificarem e se inscreverem nesse acontecimento discursivo, pois eles não conseguem se inserir neste mundo simbólico do livro didático, que não os representa.

Quando a escola não considera a visão de mundo aprendida com as relações culturais nos seus respectivos contextos sociais, o ensino passa a ser desinteressante para o aluno, porque as práticas de ensino, em parte, não somam com os seus saberes, pois muitas vezes, são deixadas de lado por razão de já existir um conhecimento produzido, padronizado, normatizado a ser transmitido para os alunos. É aqui que identificamos ser essencial o trabalho de um dos mais importantes profissionais da educação: o pedagogo (a). Que seja, preferencialmente, filho da terra, que conheça a realidade sócio-histórica desta população 
e faça a diferença, elaborando práticas discursivas e pedagógicas que sirvam de amparo, guarida e ajuda aos professores das comunidades ribeirinhas da Amazônia Tocantina. Valorizando, acima de tudo, os saberes, os dizeres e fazeres dos povos da floresta e das águas.

A prática de leitura no ensino de Língua Portuguesa é uma prática de linguagem; é o espaço da interpretação do discurso que mobiliza sentidos, possibilitando ao sujeito-aluno compreender o mundo e, novamente como disse o pescador em nosso encontro no campo de pesquisa, "a ser independente"; pois, como afirma a grande pesquisadora e analista de discurso Eni Orlandi (2010, p. 40), "o sujeito é inscrito na história", e o sistema linguístico é concebido como um sistema significante, capaz de falhas que, para significar o que lhe é próprio, é afetado pelo real da história (pela contradição) - é um sistema "pensado" no funcionamento da língua, com homens falando no mundo.

Por fim, na perspectiva de trabalhos futuros, com o desenvolvimento dos estudos aqui apresentados, temos a convicção de que cultura, memória, história e educação estão imbricadas, e de que o discurso presente no material didático afeta diretamente a constituição do sujeito-aluno em sua posição sujeito-cidadão. Com isso, para se construir um projeto educacional democrático que respeite as diferenças, a relação língua, discurso e história para o ensino de Língua Portuguesa deve estar presente na construção do livro didático de forma que garanta o direito à memória dos povos da/na Amazônia Tocantina e que vá além dos discursos fundadores e hegemônicos que não representam a cultura do sujeito-aluno daquela região. Este estudo, talvez, seja um gesto primeiro de compreensão destas relações, o qual possibilitará a nós e a pesquisadores contemporâneos a continuidade dessas reflexões com outras interlocuções, interfaces e ideias.

\section{Agradecimentos}

Agradecimentos à Rede PROCAD Amazônia (UFPA-UFMT-UFAM) e à Coordenação de Aperfeiçoamento de Pessoal de Nível Superior (CAPES) - Brasil, pelo apoio financeiro aos pesquisadores bolsistas PVNS e Doutorando.

\section{Referências}

Alves, M., A., J., \& Gewndsznayder, F. (2002). O método das ciências sociais. Pesquisa quantitativa e qualidade, Pioneira.

Dela-Silva, S. C. (2008). O acontecimento discursivo da televisão no Brasil: a imprensa na constituição da TV como grande mídia. Tese (Doutorado). IEL, Unicamp.

Domingues, A. S., Pinto, B. C. M. \& Docema, Danilo G. (2019). Espaço discursivo e/ou prática de linguagem? O festejo da Santa e da congada em Espírito Santo do Dourado - MG. Linguagens: Revista de Letras, Artes E Comunicação (FURB), 13, 334-350. https://proxy.furb.br/ojs/index.php/linguagens/article/view/9132

Freire, P. (2019). Pedagogia da autonomia: saberes necessários a prática educativa, Paz e Terra.

Gadet, F. \& Pêcheux, M. (2010). A Língua Inatingível: O Discurso na História da Linguística, RG.

Guimarães, E. (2006). Enunciação e política de línguas no Brasil. Revista Letras - Espaços de Circulação da Linguagem, n. 27, https://periodicos.ufsm.br/letras/article/view/11897

Ludke, M. \& André, M. E. D. A. (1986). Pesquisa em educação: abordagem qualitativa. EPU, LTDA.

Massmann, D. (2013). Ontem, hoje e amanhã: ainda a questão do ensino. In: Verli Petri; Cristiane Dias. (Org.). Análise de discurso em perspectiva. Teoria, método e análise. Editora da UFSM, v. 1, 159-171.

Monteiro, A. de O., Jucá, S.C.S. \& Silva, S. A. da (2019). O livro escolar e sua influência na formação dos alunos da educação básica de escolas públicas. Pesquisa, Sociedade e Desenvolvimento, [S. l.] , v. 8, n. 1, e4981643. https://rsdjournal.org/index.php/rsd/article/view/643.

Oliveira, T., Silva, E. G. O., Silva, C.O. \& Araújo, L. A. M. (2015). Tecendo Linguagens: Língua Portuguesa $9^{\circ}$ ano, IBEP.

Orlandi, E. P. (2009). A Linguagem e seu Funcionamento: As Formas do Discurso, Pontes.

Orlandi, E. P. (2007). As formas do silêncio: no movimento dos sentidos, Unicamp.

Orlandi, E. P. (2003). Discurso fundador. A formação do país e a construção da identidade nacional, Pontes. 
Research, Society and Development, v. 10, n. 7, e46310716674, 2021

(CC BY 4.0) | ISSN 2525-3409 | DOI: http://dx.doi.org/10.33448/rsd-v10i7.16674

Orlandi, E. P. (2005). A língua Brasileira. Ciências e Cultura. SBPC, 57(2) http://cienciaecultura.bvs.br/scielo.php?script=sci_arttext\&pid=S000967252005000200016

Orlandi, E. P. (2010). Análise de Discurso: princípios e procedimentos, Pontes.

Orlandi, E. P. (2012). Discurso e Leitura, Cortez.

Orlandi, E. P. \& Ferreira, E. L. (Orgs) (2014). Discurso sobre a inclusão, Intertexto.

Pêcheux, M. (2008). O discurso: estrutura ou acontecimento, Campinas, Pontes. (Trad. Orlandi, E. P. Edição original: 1983).

Pfeiffer, C. C. (2005). O saber escolarizado como espaço de institucionalização da língua. In: Guimarães, E. \& Paula, M. R. B.(orgs). Sentido e Memória, Pontes, p. 27-39.

Sarlo, B. (2016). Paisagens imaginárias. Edusp.

Silva, T. E. (2000). A produção da Leitura na Escola, pesquisas epropostas. Editora Ática. 